\title{
Psychosocial factors involved in memory and cognitive failures in people with myalgic encephalomyelitis/chronic fatigue syndrome
}

This article was published in the following Dove Press journal:

Psychology Research and Behavior Management

25 February 2014

Number of times this article has been viewed

\author{
Elizabeth A Attree' \\ Megan A Arroll' \\ Christine P Dancey' \\ Charlene Griffith' \\ Amolak S Bansal',2 \\ 'Chronic Illness Research Team, \\ School of Psychology, University \\ of East London, London, UK; \\ ${ }^{2}$ Department of Immunology and \\ the Sutton CFS Service, St Helier \\ Hospital, Carshalton, UK
}

Correspondence: Megan A Arroll University of East London, School of Psychology, Stratford Campus, Water Lane, London, UK EI5 4LZ Fax +442082234937

Email m.a.arroll@sa.uel.ac.uk
Background: Myalgic encephalomyelitis/chronic fatigue syndrome (ME/CFS) is characterized by persistent emotional, mental, and physical fatigue accompanied by a range of neurological, autonomic, neuroendocrine, immune, and sleep problems. Research has shown that psychosocial factors such as anxiety and depression as well as the symptoms of the illness, have a significant impact on the quality of life of people with ME/CFS. In addition, individuals may suffer from deficits in memory and concentration. This study set out to explore the relationships between variables which have been found to contribute to cognitive performance, as measured by prospective and retrospective memory, and cognitive failures.

Methods: Eighty-seven people with ME/CFS answered questionnaires measuring fatigue, depression, anxiety, social support, and general self-efficacy. These were used in a correlational design (multiple regression) to predict cognitive function (self-ratings on prospective and retrospective memory), and cognitive failures.

Results: Our study found that fatigue, depression, and general self-efficacy were directly associated with cognitive failures and retrospective (but not prospective) memory.

Conclusion: Although it was not possible in this study to determine the cause of the deficits, the literature in this area leads us to suggest that although the pathophysiological mechanisms of ME/CFS are unclear, abnormalities in the immune system, including proinflammatory cytokines, can lead to significant impairments in cognition. We suggest that fatigue and depression may be a result of the neurobiological effects of ME/CFS and in addition, that the neurobiological effects of the illness may give rise to both fatigue and cognitive deficits independently.

Keywords: myalgic encephalomyelitis/chronic fatigue syndrome, memory, cognitive deficits, depression

\section{Introduction}

Chronic fatigue syndrome (CFS), also known as myalgic encephalomyelitis (ME), is a condition of unknown etiology, which is highly heterogeneous and has had a controversial history producing conflicting findings not only relating to its cause, but also with regard to its course and prognosis. ${ }^{1} \mathrm{ME} / \mathrm{CFS}$ is characterized by persistent mental and physical fatigue accompanied by a range of neurological, autonomic, neuroendocrine, immune, and sleep problems. ${ }^{2}$ Epidemiological studies have shown prevalence rates of ME/CFS to be as low as three and as high as 2,800 per $100,000 .{ }^{1} \mathrm{ME} / \mathrm{CFS}$ is a highly intrusive illness that impacts on an individual's personal, social, occupational, and recreational life ${ }^{3}$ and has significant costs for wider society. ${ }^{4}$ The present study aims to explore the association between a number of different variables (self-efficacy, 
social support, anxiety, depression, and fatigue) and cognitive performance, as cognitive dysfunction is also a key issue in the illness experience of those with ME/CFS, often affecting quality of life. ${ }^{2}$

Fatigue is central to the definition, and experience, of $\mathrm{ME} / \mathrm{CFS}$. However, fatigue is not a unitary concept and can be defined in a number of ways. A distinction can be made between peripheral fatigue (characterized by failure to sustain the force of muscle contraction) and central fatigue (a feeling of constant exhaustion is an aspect of this type of fatigue). ${ }^{5}$ Researchers make a distinction between mental, or cognitive fatigue, and physical or muscle fatigue., ${ }^{6,7}$ Chaudhuri and Behan $^{5}$ state that mental fatigue is an important cognitive component of central fatigue.

The link between fatigue and cognitive function has been reported in patients with $\mathrm{HIV}^{8}$ and chronic pain. ${ }^{9}$ In the latter context, it is noteworthy that chronic widespread pain and fibromyalgia are frequent in ME/CFS. Furthermore, it has been reported that up to $80 \%$ of patients with ME/CFS have problems with memory and concentration. ${ }^{10}$ However, the evidence for objectively observable deficits in cognitive measures is inconsistent. ${ }^{11}$ Wearden and Appleby ${ }^{12}$ reported that despite patients reporting cognitive deficits, many studies that compare the performance of ME/CFS patients with healthy controls show no significant difference in tests of memory. This was supported by research by DiClementi et al, ${ }^{13}$ who found that there was no significant difference between patients with ME/CFS and controls on global tests of memory. Conversely, Sandman et $\mathrm{al}^{14}$ showed that patients with ME/CFS performed significantly worse than both depressed patients and healthy controls on recall tests and overrated their abilities despite having normal neuropsychological profiles. Finally, in a large study of people diagnosed with ME/CFS (N=307), where an extensive battery of tests had been administered, Thomas and Smith ${ }^{15}$ demonstrated clear cognitive impairment which occurred independently of psychopathology.

There are of course different measures of memory which have been tested in people with chronic illness. Most cognitive research has focused on retrospective memory; ${ }^{16}$ eg, remembering words or events that were experienced or occurred in the past. However, of greater importance in the daily lives of people with chronic illness is prospective memory, which has been defined as "remembering to carry out intended actions at an appropriate point in the future." 17 Three types of prospective memory task have been identified, which are based on differences in their contextual retrieval demands: these are event-, time-, and activity-based. ${ }^{18}$ Time-based prospective memory tasks are dependent on self-initiated monitoring, as they involve doing something at a predesignated time, such as remembering to take medication. Event-based prospective memory tasks are cued by an external situation, such as remembering to pass on a message when seeing a friend. In contrast, activitybased intentions are associated with carrying out a specific task before or after another activity, such as remembering to turn off the oven after cooking.

However, retrospective and prospective memory are not doubly dissociable. ${ }^{19}$ Carrying out a prospective memory task is dependent upon being able to remember information about the action to be performed. ${ }^{20}$ For example, remembering to post a letter would require mental representations such as location and image of a post box and the letter. However, the strength of the relationship between retrospective and prospective memory is task dependent. Remembering to post a letter may be less dependent upon retrospective memory than remembering to buy items required for an evening meal, which would require a greater number of mental representations. Attree et $\mathrm{al}^{21}$ previously assessed both prospective and retrospective memory in eleven women with ME/CFS and 12 healthy women using a computer-generated virtual environment. People with ME/CFS performed slightly worse than healthy controls on prospective memory, although this was not statistically significant. However, the ME/CFS group performed significantly worse than the healthy controls on both a free recall task and a subjective assessment of both retrospective and prospective memory.

There is evidence to show that depression is linked with cognitive measures (in $\mathrm{ME} / \mathrm{CFS}^{3}$ and in multiple sclerosis $[\mathrm{MS}]^{22}$ ) and unsurprisingly, many patients with a chronic illness show higher levels of depression than healthy people. ${ }^{22}$ It is also well documented within the literature that depressed patients have problems with memory and concentration. While the mechanism is unclear, Porter et $\mathrm{al}^{23}$ state that changes in cognitive function may be mediated by symptom-related factors and neurobiological factors, such as hippocampal atrophy and hormonal changes in the hypothalamic-pituitaryadrenal axis.

Diamond et $\mathrm{al}^{24}$ reported that increased levels of fatigue and depressed mood were correlated with fewer words remembered in short- and long-term memory recall tests in people with MS. Bol et al, ${ }^{22}$ also investigating MS, found that anxiety, depression, and mental fatigue contributed to cognitive complaints, but not to cognitive performance. 
Both fatigue and depression then, are likely to influence memory scores in people with ME/CFS, and any differences found between groups might be explained - partially at least - by fatigue. Since fatigue is so central to ME/CFS, it may make a larger contribution to cognitive function than in other illnesses where the fatigue is not a central feature of the illness. Chaudhuri and Behan ${ }^{5}$ stated that central fatigue may occur due to a failure in the integration of the limbic input and the motor functions within the basal ganglia affecting the striatal-thalamic-frontal cortical system. Nes et $\mathrm{al}^{25}$ stated that the damage to the prefrontal cortex causes "deficits in organizing and executing appropriate behavior such as impulsivity, perseveration, poor judgment, interference with problem-solving, and disinhibition." Executive control (coordinated by the prefrontal cortex) is prone to fatigue as this capacity is limited. Nes et $\mathrm{al}^{25}$ stated that the ability to manage conditions such as ME/ CFS depends on executive function. Supporting evidence for this was found by Okada et al, ${ }^{26}$ who found that ME/ CFS patients had reduced gray matter volume in the bilateral prefrontal cortex and that the volume reduction paralleled the severity of the fatigue.

Other factors are also likely to be related to fatigue and cognitive function, including self-efficacy. General selfefficacy refers to the confidence individuals have about their ability to cope across different situations. It reflects the belief that the individual will cope with demands by taking adaptive action. ${ }^{27}$ General self-efficacy ${ }^{28}$ has been shown to be reliable and valid in many studies in numerous countries, ${ }^{29}$ and this scale has been shown to be a universal construct which is also related to optimism, self-esteem, and depression. ${ }^{30}$ Low general self-efficacy is associated with depression, anxiety, and helplessness ${ }^{31}$ and has been shown both to be a moderator of other variables ${ }^{32,33}$ and a mediator variable. ${ }^{33,34}$ Arnstein et al $^{34}$ found that self-efficacy was a mediator between pain and depression. Depression, social support, and self-efficacy are associated with each other, and may act together in influencing cognitive performance; eg, there is also some evidence for a relationship between social support and cognitive ability. ${ }^{35,36}$ Desrichard and Köpetz ${ }^{37}$ have shown that memory performance and memory-self efficacy are positively related, and another study showed that memory performance can be increased by self-efficacy enhancing interventions. ${ }^{38}$ Self-efficacy enhancing interventions have been shown to induce positive change in other instances such as better walking performance for patients with chronic obstructive pulmonary disease ${ }^{39}$ and quality of life for asthma sufferers. ${ }^{40}$
This study set out to explore the relationships between variables which have been found to contribute to cognitive performance, as measured by prospective and retrospective memory, and cognitive failures. Based on the literature, we hypothesized that cognitive performance of participants with $\mathrm{ME} / \mathrm{CFS}$ would be predicted by a combination of factors, which included the positive factors of self-efficacy and social support and the negative factors of anxiety, depression, and fatigue. Furthermore, we predicted that fatigue would be the strongest predictor of poor memory and cognitive failures, and that general self-efficacy would mediate between fatigue (and depression) and cognitive measures.

\section{Methods \\ Study design and participant selection}

This study constituted a cross-sectional survey design which was approved by the University of East London ethics committee. Potential participants were recruited from an existing database of 138 people who had previously expressed an interest in taking part in research related to ME/CFS. This database is held by the Chronic Illness Research Team in password-protected files on university computers only which are also protected by a firewall. This is a general database in which anyone who is interested in the researchers' work can be included and then contacted with details of future studies. To meet the inclusion criteria participants had to have a diagnosis of ME/CFS by a qualified medical practitioner, be suffering from ME/CFS for at least the past year, and had to be over 18 years of age.

\section{Measures}

\section{Fatigue (Chalder Fatigue Scale)}

The Chalder Fatigue $\mathrm{Scale}^{41}$ is a self-report questionnaire measuring severity of fatigue. Consisting of 14 items, participants are asked to think about the last week and to tick the box which most closely relates to each question (eg, "did you need to rest more?"; "did you have less strength in your muscles?"). Answers are on a 4-point scale to choose from for each item, "better than usual" to "much worse than usual." This scale illustrates very good internal consistency (Cronbach's alphas $=0.88-0.90$ ) and successfully discriminates between those with and without fatigue. ${ }^{42}$

\section{Depression (Center for Epidemiologic Studies Depression scale)}

The Center for Epidemiologic Studies Depression (CES-D) scale is self-report measure comprising 20 items designed to measure depressive symptoms in the general population. ${ }^{43}$ 
Participants are asked to rate each item on how often they have felt that way in the past week. Answers range from "rarely or none of the time" to "all of the time." The internal consistency of the CES-D is good, with reliability analyses yielding Cronbach's alphas of 0.63 to $0.93 .{ }^{43}$ Temporal stability analysis (over a 3-month period) resulted in a correlation of 0.61 , which is also acceptable. ${ }^{44}$

\section{Anxiety (Hospital Anxiety and Depression Scale)}

The Hospital Anxiety and Depression Scale (HADS) ${ }^{45}$ was used to measure anxiety. This is a self-report measure which measures participants' feelings of anxiety or depression over the past week. Ratings are on a 1-4 Likert scale. The internal consistency of the anxiety subscale is good, resulting in Cronbach's alphas of 0.76 to 0.93 in its English versions. ${ }^{46}$ Concurrent validity of the anxiety subscale is also good, with correlations of 0.69 and 0.75 with the Clinical Anxiety Scale and 0.64 to 0.81 with the Spielberger's State-Trait Anxiety Inventory. ${ }^{46}$

\section{Social support (Medical Outcome Study)}

The Medical Outcome Study (MOS) social support survey ${ }^{47}$ is a 19-item scale that was developed for patients with chronic conditions. Participants are asked to rate each item on a 5-point scale ranging from "none of the time" to "all of the time." Internal consistency for this measure is very good, with Cronbach's alphas of between $0.91-0.97$, as is temporal stability at 1 year with correlations of between $0.72-0.78$. Convergent validity is also good, with correlations between the MOS and measures of loneliness $=-0.67$, family functioning $=0.53$, and marital functioning $=0.56 .{ }^{47}$

\section{General self-efficacy scale}

Developed by Schwarzer and Jerusalem, ${ }^{28}$ the general selfefficacy scale (GSE) is a 10-item measure where participants are asked to rate each item by choosing one of four answers ranging from "not at all true" to "exactly true." The GSE typically yields high internal consistency coefficients of between $0.75-0.91$ and test-retest reliability correlations of between $0.55-0.75 .^{27}$

\section{Cognitive function}

\section{Prospective and retrospective memory} questionnaire

Smith et $\mathrm{al}^{48}$ developed a scale in order to assess the prospective and retrospective memory of patients with dementia. It is a 16-item scale that asks participants how often each item happens to them; eg, "Do you decide to do something in a few minutes' time and then forget to do it?" Answers are on a 5-point scale ranging from "never" to "very often." The internal consistency is very good for this scale, with Cronbach's alphas of 0.89 for the total scale, 0.84 for prospective memory scale, and 0.80 for the retrospective memory scale. ${ }^{49}$ The ability of this measure to predict actual memory deficits varies between the two subscales, with the prospective memory scale illustrating better performance than the retrospective scale. ${ }^{50}$

\section{Cognitive Failures Questionnaire}

The Cognitive Failures Questionnaire (CFQ) ${ }^{51}$ is a 25 -item questionnaire which measures failures of perception, memory, and motor function. Participants are asked to rate how often they experience each type of error on a 5-point Likert-type scale ranging from 0 ("never") to 4 ("very often"); eg, "do you find you confuse right and left when giving directions?" The total score for this questionnaire ranges from 0-100 with higher scores indicating more types of cognitive failures. The construct validity of this measure is good, illustrating significant positive correlations with the affective response, perception of time, and constraint subscales of the Boredom Proneness Scale and the attention and hyperactivity subscales of the Adult Behavior Checklist. ${ }^{52}$ In terms of the questionnaire's association with actual mishaps (eg, an accident, an injury-caused hospitalization, a serious fall), CFQ scores differed significantly (in the expected direction) between participants defined as mishap-involved as compared to those defined as mishap-free. ${ }^{53}$

\section{Procedure}

A letter, an information sheet, a consent form, personal details form, a prepaid envelope, and the questionnaires described above were posted to 138 people on the database. The questionnaires were packed according to a Latin-square design; eg, participant one would receive the Chalder Fatigue Scale followed by the CES-D, HADS, MOS, GSE, prospective and retrospective memory questionnaire (PRMQ), and CFQ. Participant two would receive the CES-D, HADS, MOS, GSE, PRMQ, CFQ, and the Chalder Fatigue Scale, and so on. Participants were instructed to complete the questionnaires in the order in which they appeared in the pack. Eighty-seven participants ( 85 women and two men) returned questionnaire packs by the 4 -week deadline that was given. This represents a $63 \%$ response rate. No reminders were issued in this study. All data was entered manually into SPSS for Windows version 18.0 (IBM Corporation, Armonk, NY, USA) by two members of the research team and cross-checked. 


\section{Results}

A total of 87 respondents completed and returned the questionnaire packs; 85 women (97.7\%) and two men (2.3\%). The mean age of the sample was 54.80 years (standard deviation $=10.32$ years). The data were analyzed using SPSS for Windows version 18.0. Pearson's $r$ correlations and hierarchical multiple regressions were used to demonstrate the relationships between the variables. ${ }^{54}$ Descriptive statistics are shown in Table 1.

We computed full correlations for the psychosocial variables with cognitive measures (see Table 2). As can be seen from Table 2, higher levels of depression and fatigue were associated with a worsening of cognitive performance. Social support showed no important or significant relationships with any of the variables and was therefore excluded from further analysis. Pearson's correlations (one-tailed) were computed for the psychosocial variables (see Table 3).

Since the variables were intercorrelated, we chose standard multiple regression to determine the unique contribution of fatigue, general self-efficacy, depression, and anxiety to our cognitive measures.

\section{Prospective memory}

As noted in the introduction, retrospective and prospective memory are not dissociable, although the strength of the correlation between these may vary. Retrospective memory was entered in the model at step 1 as a covariate. Depression, fatigue, self-efficacy, and anxiety were entered at step 2.

As expected, retrospective memory was highly correlated with prospective memory $\left(R=0.868, \operatorname{Adj} R^{2}=0.750\right.$; $\left.F_{1,80}=241.365, P<0.001\right)$. At step 2, the other predictor variables raised the correlation to 0.872 only, and this small change was not statistically significant. The final model is shown in Table 4. None of the predictor variables, once

Table I Means and standard deviations for each variable

\begin{tabular}{lrrll}
\hline Variable & Mean & $\begin{array}{c}\text { Standard } \\
\text { deviation }\end{array}$ & \multicolumn{2}{c}{$\begin{array}{l}\text { 95\% confidence } \\
\text { interval }\end{array}$} \\
\cline { 4 - 5 } & & & Lower & Upper \\
\hline Age & 54.80 & 10.32 & 52.31 & 57.00 \\
Duration of illness & 16.67 & 9.96 & 14.77 & 19.24 \\
Fatigue & 36.70 & 7.47 & 34.99 & 38.16 \\
Social support & 61.15 & 20.52 & 52.26 & 65.39 \\
Retrospective memory & 21.79 & 8.56 & 19.90 & 23.70 \\
Prospective memory & 26.18 & 8.64 & 24.24 & 29.13 \\
Cognitive failures & 57.37 & 18.88 & 52.90 & 61.45 \\
Anxiety & 17.42 & 2.55 & 16.95 & 18.07 \\
Depression & 21.87 & 9.80 & 19.59 & 24.01 \\
Self-efficacy & 26.51 & 6.12 & 24.99 & 27.81 \\
\hline
\end{tabular}

Table 2 Pearson's $r$ correlations (two-tailed) between the psychosocial and cognitive variables

\begin{tabular}{lccc}
\hline & $\begin{array}{l}\text { Cognitive } \\
\text { failures }\end{array}$ & \multicolumn{1}{l}{$\begin{array}{l}\text { Prospective } \\
\text { memory }\end{array}$} & \multicolumn{1}{l}{$\begin{array}{l}\text { Retrospective } \\
\text { memory }\end{array}$} \\
\hline Depression & $0.479 ; P<0.00 \mathrm{I}$ & $0.358 ; P=0.00 \mathrm{I}$ & $0.376 ; P<0.00 \mathrm{I}$ \\
Fatigue & $0.388 ; P<0.00 \mathrm{I}$ & $0.298 ; P=0.005$ & $0.354 ; P=0.00 \mathrm{I}$ \\
Social support & $0.030 ; P=0.79 \mathrm{I}$ & $-0.062 ; P=0.566$ & $-0.042 ; P=0.703$ \\
General & $-0.385 ; P<0.00 \mathrm{I}$ & $-0.277 ; P=0.009$ & $-0.320 ; P=0.003$ \\
self-efficacy & & & \\
Anxiety & $-0.225 ; P=0.043$ & $-0.187 ; P=0.088$ & $-0.259 ; P=0.018$ \\
\hline
\end{tabular}

retrospective memory was controlled for, were statistically significant. The beta weights show that the lines of best fit are virtually flat.

\section{Retrospective memory}

The exploratory variables significantly predicted retrospective memory ( $R=0.470$, Adj $R^{2}=0.18$ ). The analysis of variance (ANOVA) showed that $F_{4,76}=5.392, P=0.001$. The regression analysis is shown in Table 5. Here the strongest predictor was not depression, but fatigue, which independently and significantly predicted scores on retrospective memory.

\section{Cognitive failures}

The predictor variables significantly predicted cognitive failures $\left(R=0.558\right.$, Adj $\left.R^{2}=0.27\right)$. The ANOVA showed that $F_{4,75}=8.459$, $P<0.001$. The regression analysis is shown in Table 6 .

Depression shows the strongest relationship with cognitive failures, and in this analysis, only anxiety was nonsignificant. Without consideration of the other variables, depression on its own relates strongly to all three memory measures. However, it is only in the last analysis - cognitive failures - that it becomes possible to elucidate the way in which the independent variables relate to memory because it is only with cognitive failures that the predictors (except for anxiety), contribute independently and significantly to cognitive performance.

From the results for all three cognitive measures, it seems that depression and fatigue in particular are involved in memory problems. It is not easy to determine a causal link between these two variables, so that in our path diagram we

Table 3 Pearson's $r$ correlations between the psychosocial variables

\begin{tabular}{llll}
\hline & Fatigue & General self-efficacy & Anxiety \\
\hline Depression & $0.436 ;$ & $-0.456 ; P<0.001$ & $-0.55 I ; P<0.001$ \\
& $P<0.001$ & & \\
Fatigue & & $-0.138 ; P=0.101$ & $-0.219 ; P=0.023$ \\
General & & & $-0.350 ; P=0.00$ I \\
self-efficacy & & & \\
\hline
\end{tabular}


Table 4 Criterion variable $=$ prospective memory. A two-step multiple regression analysis $(\mathrm{N}=8 \mathrm{I})$

\begin{tabular}{|c|c|c|c|c|c|c|}
\hline \multirow[t]{2}{*}{ Model } & \multirow[t]{2}{*}{$\begin{array}{l}\text { Unstandardized } \\
\text { coefficients (beta) }\end{array}$} & \multirow[t]{2}{*}{$\begin{array}{l}\text { Standardized } \\
\text { coefficients (beta) }\end{array}$} & \multirow[t]{2}{*}{$t$} & \multirow[t]{2}{*}{$P$-value } & \multicolumn{2}{|c|}{$\begin{array}{l}95 \% \text { confidence } \\
\text { interval }\end{array}$} \\
\hline & & & & & Lower & Upper \\
\hline I. Constant & 6.687 & & 5.002 & $<0.001$ & 4.03 & 9.35 \\
\hline Retrospective memory & 0.892 & 0.868 & 15.536 & $<0.001$ & 0.78 & 1.01 \\
\hline 2. Constant & 2.252 & & 0.383 & 0.703 & -9.46 & 13.96 \\
\hline Retrospective memory & 0.893 & 0.869 & 13.570 & $<0.001$ & 0.76 & 1.03 \\
\hline Fatigue & -0.065 & -0.054 & -0.824 & 0.413 & 0.22 & 0.09 \\
\hline General self-efficacy & 0.010 & 0.007 & 0.105 & 0.916 & -0.17 & 0.19 \\
\hline Depression & 0.090 & 0.101 & 1.272 & 0.207 & -0.05 & 0.23 \\
\hline Anxiety & 0.261 & 0.074 & 1.088 & 0.280 & -0.22 & 0.74 \\
\hline
\end{tabular}

Notes: Step I accounts for $75 \%$ of the variance; step 2 accounts for a further $6 \%$ (adjusted $R^{2}$ squares).

included them as co-moderators of, and self-efficacy as a mediator variable on, cognitive failures. The path coefficients are partial, standardized beta weights and therefore can be compared directly with each other. The beta weights were calculated by performing standard multiple regression analyses within SPSS, a) using fatigue, depression, and general self-efficacy as predictor variables, and cognitive failures as the criterion variable and $b$ ) using fatigue and depression as the predictor variables, and general self-efficacy as the criterion variable. Both regression analyses were statistically significant $\left(\mathrm{R}=0.553, \mathrm{~F}_{3,77}=11.30\right.$ and $\mathrm{R}=0.457, \mathrm{~F}_{2,80}=10.576$, respectively, both $P<0.001$ ) (see Figure 1).

However, the direct effect of fatigue on cognitive failures (without consideration of other variables) was statistically significant (beta $=0.228, P=0.037$ ). The indirect effects were not statistically significant individually. In the path diagram, with all effects included, general self-efficacy is shown to be a partial mediator, since the direct and indirect effects together significantly predict cognitive functioning (beta $=0.389, P<0.001$ ).

\section{Discussion}

The proposed model shows that fatigue, depression, and general self-efficacy relate directly to cognitive failures.
Fatigue and depression may be a result of the neurobiological effects of ME/CFS. It is well-documented that people with chronic illnesses have higher levels of depression, and that people with ME/CFS tend to be more depressed than many other illness groups. Depression is known to directly affect neuropsychological performance, and our study confirmed this also. There have been many reasons put forward for these findings ${ }^{55} \mathrm{~A}$ lack of general motivation associated with depression may lead to a lowering of self-efficacy, which in turn, leads to cognitive failures. Fatigue, depression, and selfefficacy have direct effects on cognitive failures, fatigue being positively associated with the number of cognitive failures made. This confirms previous research discussed earlier, and was expected. Of course, depression itself may have a bidirectional relationship with self-efficacy, and certainly with fatigue. It is interesting that fatigue had no significant relationship to self-efficacy, whereas depression did. Higher scores on self-efficacy were associated with a lower number of cognitive failures. However, both of the direct effects were weak. Despite that, it might be that self-efficacy enhancing interventions would produce positive changes in cognitive performance, and in other dimensions such as those shown in patients with other illnesses..$^{38-40}$

Table 5 Retrospective memory: standard multiple regression $(\mathrm{N}=8 \mathrm{I})$

\begin{tabular}{lccrrrr}
\hline Model & $\begin{array}{l}\text { Unstandardized } \\
\text { coefficients (beta) }\end{array}$ & $\begin{array}{l}\text { Standardized } \\
\text { coefficients (beta) }\end{array}$ & $\boldsymbol{t}$ & P-value & $\begin{array}{l}\text { 95\% confidence } \\
\text { interval }\end{array}$ \\
\cline { 3 - 7 } & & & & & Lower & Upper \\
\hline Constant & 15.766 & - & 1.564 & 0.122 & -4.31 \\
Fatigue & 0.298 & 0.255 & 2.221 & 0.029 & 0.03 & 0.57 \\
General self-efficacy & -0.277 & -0.203 & -1.756 & 0.083 & -0.59 & 0.04 \\
Depression & 0.138 & 0.159 & 1.127 & 0.263 & -0.11 & 0.38 \\
Anxiety & -0.038 & -0.011 & -0.091 & 0.927 & 0.87 & 0.80 \\
\hline
\end{tabular}

Note: This model accounts for $22 \%$ of the variance (adjusted $R^{2}$ ). 
Table 6 Cognitive failures: standard multiple regression $(\mathrm{N}=80)$

\begin{tabular}{|c|c|c|c|c|c|c|}
\hline \multirow[t]{2}{*}{ Model } & \multirow[t]{2}{*}{$\begin{array}{l}\text { Unstandardized } \\
\text { coefficients (beta) }\end{array}$} & \multirow[t]{2}{*}{$\begin{array}{l}\text { Standardized } \\
\text { coefficients (beta) }\end{array}$} & \multirow[t]{2}{*}{$t$} & \multirow[t]{2}{*}{$P$-value } & \multicolumn{2}{|c|}{$\begin{array}{l}95 \% \text { confidence } \\
\text { interval }\end{array}$} \\
\hline & & & & & Lower & Upper \\
\hline Constant & 13.312 & - & 1.463 & 0.148 & -11.33 & 73.95 \\
\hline Fatigue & 0.579 & 0.220 & 2.030 & 0.046 & 0.01 & 1.147 \\
\hline General self-efficacy & -0.727 & -0.240 & -2.187 & 0.032 & -1.39 & -0.07 \\
\hline Depression & 0.601 & 0.311 & 2.328 & 0.023 & 0.087 & 1.12 \\
\hline Anxiety & 0.618 & 0.081 & 0.701 & 0.485 & -1.14 & 2.37 \\
\hline
\end{tabular}

Note: This model accounts for $27.4 \%$ of the variance (adjusted $R^{2}$ ).

In this study, fatigue appears to affect retrospective memory which confirms research from studies on other illnesses. ${ }^{24}$ However, the other psychosocial variables seem to have little effect on retrospective memory. It is puzzling why the results for retrospective memory were weaker than those for cognitive failures. As the explanatory variables were correlated with each other and did not independently predict prospective and retrospective memory, it is not easy to disentangle the relationships between them. However, it appears that prospective memory is not affected by fatigue or depression, once the retrospective part of prospective memory is controlled for. This contradicts the findings of previous research by Attree et al, ${ }^{21}$ although this may be explained by the fact that these researchers did not partial out retrospective memory scores in their analysis. However, it may be because in the current study we have a general measure of fatigue. Future studies should measure the different aspects of fatigue, as it could be possible that more specific measures of fatigue (eg, cognitive fatigue) may actually have an effect on prospective memory, even if retrospective memory is controlled for.

Although it is clear that people with ME/CFS rate both their prospective and retrospective memory as worse than healthy controls, since the measure is self-reported, we have no objective evidence to confirm actual memory performance. Findings from studies which have investigated the difference between subjective and objective measures of memory in this group have been inconclusive. ${ }^{11}$ Nevertheless, in other

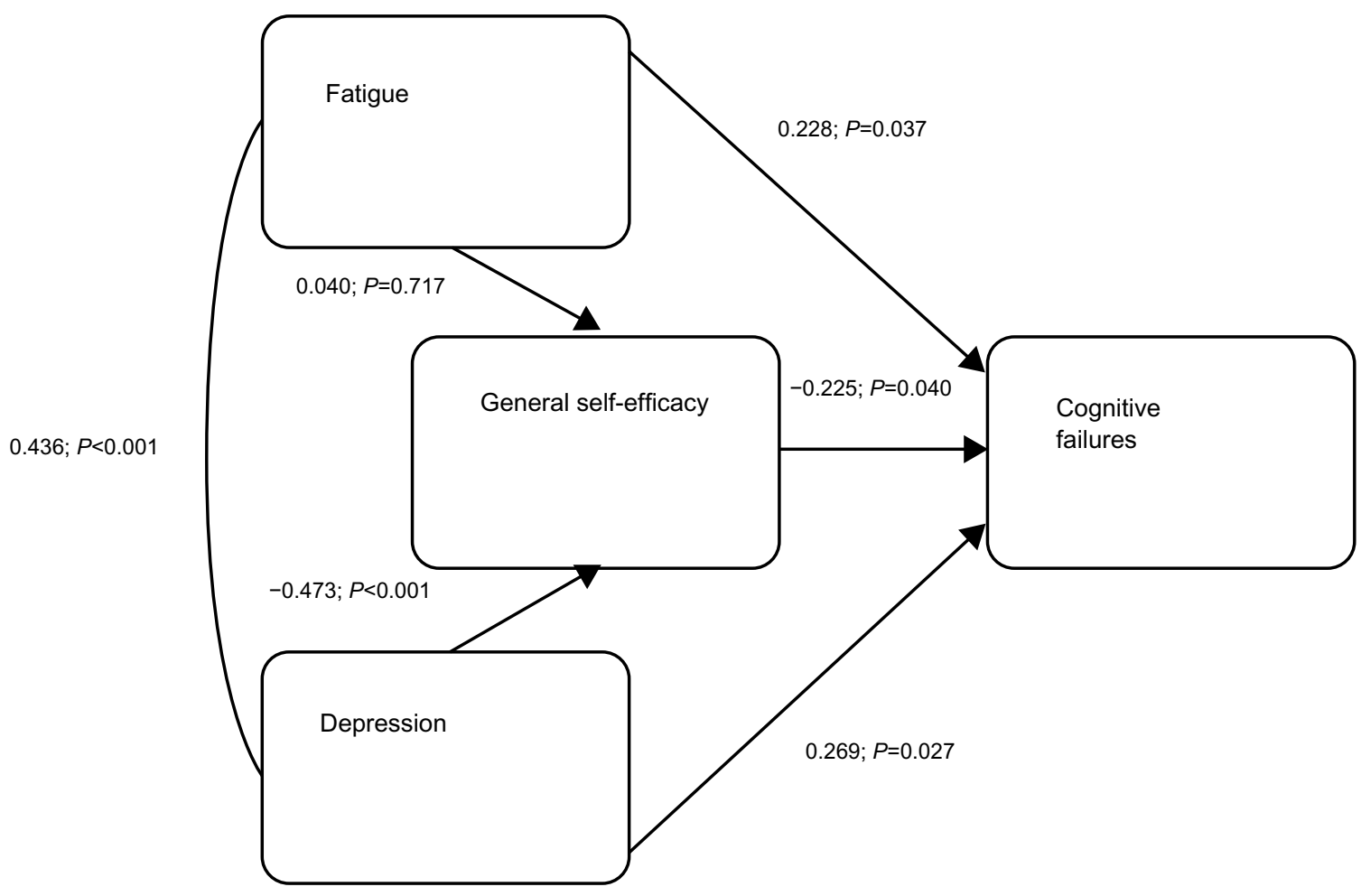

Figure I Path diagram: fatigue, depression, general self-efficacy and their relationship to cognitive failures. 
patient groups self-reported memory problems appear to be related to objective memory assessments. ${ }^{56}$

There may be several reasons why people with chronic illness perform poorly on tests of memory. For some illnesses, such as MS, structural changes in the brain could account for poor neuropsychological performance. Both depression and fatigue, and also certain centrally-acting medications, can account for a worsening of cognitive function. Deficits due to these latter causes are common to most chronic illnesses. This is supported by a wealth of research showing a range of cognitive deficits in illnesses such as inflammatory bowel disease and irritable bowel syndrome, ${ }^{57}$ fibromyalgia, ${ }^{58}$ Parkinson's disease, ${ }^{59}$ and $\mathrm{MS},{ }^{24}$ all of which have depression and fatigue in common.

The fact that fatigue relates to cognitive failures confirms the findings of previous studies. However, what is the mechanism of action here? Wearden and Appleby ${ }^{12}$ stated that ME/ CFS patients may perform cognitive tasks at a similar level to healthy controls, but "only by virtue of diverting extra processing resources to the task, which is perceived as fatiguing." The central fatigue of ME/CFS is not, by definition, simply somatic. It is often described by people with ME/CFS as "brain fog" - that is, the affected person cannot think properly and mental tasks are just as difficult as physical tasks. Interestingly, Bol et al, ${ }^{22}$ studying people with MS, found that mental fatigue, rather than physical fatigue, related to self-reported cognitive impairment. If people with ME/CFS are asked to perform numerous or complex tasks, which are fatiguing, then participants are likely to either perform worse on the tasks, and/or become fatigued. Alternately, they may use all their resources to do well on the set tasks, but after finishing the tasks, their symptoms are likely to worsen and this group of people will need to rest more than is usual.

Contrary to expectations and previous research, it appears that social support does not contribute to cognitive measures, or indeed to the other explanatory variables. This was therefore excluded at an early stage of our analyses. Management programs which focus on dealing with factors such as selfefficacy, depression, and symptom expectation may improve cognitive function and the quality of life of people with $\mathrm{ME}$ / CFS. It will be interesting to see if this is accompanied by improvements in memory.

\section{Limitations of the study and future work}

Since the participants with ME/CFS were a self-selected group, that is, they had previously expressed their desire to take part in $\mathrm{ME} / \mathrm{CFS}$ research, this group may not be representative of all people with $\mathrm{ME} / \mathrm{CFS}$. Also it was not possible in this study to obtain independent verification of diagnosis. However, we believe the diagnosis of ME/CFS is likely sound given the duration of the symptoms and the absence of an alternative diagnosis proffered to patients by their medical practitioners. A further limitation is that we did not obtain ratings of severity of illness. Future studies will need to take these factors into account and also examine changes in cognition and memory with the post-exertional malaise that typifies ME/CFS. Finally, the response rate could have been improved if reminders had been sent to participants and we will endeavor to do this in future studies.

Although our model shows that fatigue leads to cognitive failures, it may be that the illness itself (which may include changes in the hypothalamic-pituitary-adrenal axis, neuroendocrine dysregulation, and other neurobiological effects) may give rise to both fatigue and cognitive deficits, independently; ie, that the correlation between fatigue and cognitive failures are both due to a third variable - the neurobiological effects of ME/CFS. Therefore, other areas of future work may want to focus on these effects and also the pathophysiological mechanism(s) of ME/CFS to discover how these relate to fatigue and cognitive performance; for instance, various studies have reported abnormalities in the immune system, including elevated proinflammatory cytokines, which could explain fatigue. ${ }^{60}$ The importance of elevated proinflammatory cytokines in the etiology of fatigue is also strongly suggested by work in patients with MS with and without fatigue. ${ }^{61}$ It is presently unclear whether the low level increase in inflammatory cytokines seen in $\mathrm{ME} / \mathrm{CFS}^{62}$ and associated with an increase in highly sensitive $\mathrm{C}$-reactive protein, a general marker for inflammation and infection, ${ }^{63}$ can cause significant impairment of cognition and memory in individuals with $\mathrm{ME}$ / CFS; this would be a worthwhile area of future study.

\section{Disclosure}

The authors report no conflicts of interest in this work.

\section{References}

1. Jason LA, Fennell PA, Taylor RR. Handbook of Chronic Fatigue Syndrome. Hoboken: NJ Wiley; 2003.

2. Carruthers BM, Jain AK, de Meirleir KL, et al. Myalgic Encephalomyelitis/Chronic Fatigue Syndrome: Clinical Working Case Definition, Diagnostic and Treatment Protocols. J Chronic Fatigue Syndr. 2003;11(1):7-115.

3. Dancey CP, Friend J. Symptoms, impairment and illness intrusiveness their relationship with depression in women with ME/CFS. Psychology and Health. 2008;23(8):983-999.

4. Reynolds KJ, Vernon SD, Bouchery E, Reeves WC. The economic impact of chronic fatigue syndrome. Cost Eff Resour Alloc. 2004;2(1):4.

5. Chaudhuri A, Behan PO. Fatigue and basal ganglia. J Neurol Sci. 2000;179(1-2):34-42. 
6. Bryant D, Chiaravalloti ND, DeLuca J. Objective measurement of cognitive fatigue in multiple sclerosis. Rehabilitation Psychology. 2004; 49(2):114-122.

7. Giovannoni G. Multiple sclerosis related fatigue. J Neurol Neurosurg Psychiatry. 2006;77(1):2-3.

8. Woods SP, Iudicello JE, Moran LM, Carey CL, Dawson MS, Grant I; The HIV Neurobehavioral Research Center (HNRC) Group. HIVassociated prospective memory impairment increases risk of dependence in everyday functioning. Neuropsychology. 2008;22(1):110-117.

9. Roth RS, Geisser ME, Theisen-Goodvich M, Dixon PJ. Cognitive complaints are associated with depression, fatigue, female sex, and pain catastrophizing in patients with chronic pain. Arch Phys Med Rehabil. 2005;86(6):1147-1154.

10. Short K, McCabe M, Tooley G. Cognitive functioning in chronic fatigue syndrome and the role of depression, anxiety, and fatigue. J Psychosom Res. 2002;52(6):475-483.

11. Majer M, Welberg LAM, Capuron L, Miller AH, Pagnoni G, Reeves WC. Neuropsychological performance in persons with chronic fatigue syndrome: Results from a population-based study. Psychosom Med. 2008;70(7):829-836.

12. Wearden AJ, Appleby L. Research on cognitive complaints and cognitive functioning in patients with chronic fatigue syndrome (CFS): What conclusions can we draw? J Psychosom Res. 1996;41(3):197-211.

13. DiClementi JD, Schmaling KB, Jones JF. Information processing in chronic fatigue syndrome: a preliminary investigation of suggestibility. J Psychosom Res. 2001;51(5):679-686.

14. Sandman CA, Barron JL, Nackoul K, Goldstein J, Fidler F. Memory deficits associated with chronic fatigue immune dysfunction syndrome Biol Psychiatry. 1993;33(8-9):618-623.

15. Thomas M, Smith A. An investigation into the cognitive deficits associated with chronic fatigue syndrome. Open Neurol J. 2009;3:13-23.

16. Crowe SF, Casey A. A neuropsychological study of the chronic fatigue syndrome: support for a deficit in memory function independent of depression. Australian Psychologist. 1999;34(1):70-75.

17. McDaniel MA, Einstein GO. Prospective Memory: An Overview and Synthesis of an Emerging Field. Thousand Oaks: SAGE; 2007.

18. Kvavilashvili L, Ellis J. Varieties of Intention: Some Distinctions and Classifications. In: Brandimonte M, Einstein GO, McDaniel MA, editors. Prospective Memory: Theory and Applications. Hillsdale: Lawrence Erlbaum; 1996:23-51.

19. Burgess PW, Shallice T. The relationship between prospective and retrospective memory: neuropsychological evidence. In: Conway MA, editor. Cognitive Models of Memory. Cambridge: MIT Press; 1997 247-272.

20. Einstein GO, McDaniel MA. Normal aging and prospective memory. J Exp Psychol Learn Mem Cogn. 1990;16(4):717-726.

21. Attree EA, Dancey CP, Pope AL. An assessment of prospective memory retrieval in women with chronic fatigue syndrome using a virtual-reality environment: an initial study. Cyberpsychol Behav. 2009;12(4):379-385.

22. Bol U, Duits AA, Hupperts RMM, Verlinder I, Verhey FRJ. The impact of fatigue on cognitive functioning in patients with multiple sclerosis. Clin Rehabil. 2010;24(9):854-862.

23. Porter RJ, Bourke C, Gallagher P. Neuropsychological impairment in major depression: its nature, origin and clinical significance. Aust NZ J Psychiatry. 2007;41(2):115-128.

24. Diamond BJ, Johnson SK, Kaufman M, Graves L. Relationships between information processing, depression, fatigue and cognition in multiple sclerosis. Arch Clin Neuropsychol. 2008;23(2):189-199.

25. Nes LS, Roach AR, Segerstrom SC. Executive functions, self-regulation and chronic pain: a review. Ann Behav Med. 2009;37(2):173-183.

26. Okada T, Tanaka M, Kuratsune H, Watanabe Y, Sadato N. Mechanisms underlying fatigue: a voxel-based morphometric study of chronic fatigue syndrome. BMC Neurol. 2004;4(1):14.

27. Scholz U, Doña BG, Sud S, Schwarzer R. Is general self-efficacy a universal construct? Psychometric findings from 25 countries. Eur J Psychol Assess. 2002;18(3):242-251.
28. Schwarzer R, Jerusalem M. Generalized Self-Efficacy Scale. In: Weinman J, Wright S, Johnston M, editors. Measures in Health Psychology: A User's Portfolio. Causal and Control Beliefs. Windsor, UK: NFER-Nelson; 1995:35-37.

29. Schwarzer R, Mueller J, Greenglass E. Assessment of perceived general self-efficacy on the internet: Data collection in cyberspace. Anxiety Stress Coping. 1999;12:145-161.

30. Luszczynska A, Gutiérez-Doña B, Schwarzer R. General self-efficacy in various domains of human functioning: Evidence from five countries. International Journal of Psychology. 2005;40(2):80-89.

31. Schwarzer R, Hallum S. Perceived teacher self-efficacy as a predictor of job stress and burnout: mediation analyses. Applied Psychology. 2008;57:152-171.

32. Grau R, Salanova M, Peiró JM. Moderator effects of self-efficacy on occupational stress. Psychology in Spain. 2001;5(1):63-74.

33. Speier C, Frese M. Generalized self-efficacy as a mediator and moderator between control and complexity at work and personal initiative: a longitudinal field study in East Germany. Human Performance. 1997;10(2):171-192.

34. Arnstein P, Caudill M, Mandle CL, Norris A, Beasley R. Self efficacy as a mediator of the relationship between pain intensity, disability and depression in chronic pain patients. Pain. 1999;80(3):483-491.

35. Seeman TE, Lusignolo TM, Albert M, Berkman L. Social relationships, social support, and patterns of cognitive aging in healthy, highfunctioning older adults: MacArthur studies of successful aging. Health Psychol. 2001;20(4):243-255.

36. Stevens F, Kaplan C, Ponds R, Jolles J. The importance of active lifestyles for memory performance and memory self-knowledge. Basic and Applied Social Psychology. 2001;23(2):137-145.

37. Desrichard O, Köpetz C. A threat in the elder: the impact of taskinstructions, self-efficacy and performance expectations on memory performance in the elderly. European Journal of Social Psychology. 2005;35(4):537-552.

38. West RL, Bagwell DK, Dark-Freudeman A. Self-efficacy and memory aging: the impact of a memory intervention based on selfefficacy. Neuropsychol Dev Cogn B Aging Neuropsychol Cogn. 2008; 15(3):302-329.

39. Davis A, Carrieri-Kohlman, Janson V, Gold W, Stulbarg M. Effects of treatment on two types of self-efficacy in people with chronic obstructive pulmonary disease. J Pain Symptom Manage. 2006;32(1):60-70.

40. Martin MA, Catrambone CD, Kee RA, et al; Chicago Initiative to Raise Asthma Health Equity Investigative Team. Improving asthma self-efficacy: developing and testing a pilot community-based asthma intervention for African American adults. J Allergy Clin Immunol. 2009;123(1):153. e3-159. e3.

41. Chalder T, Berelowitz G, Pawlikowska T, et al. Development of a fatigue scale. J Psychosom Res. 1993;37(2):147-153.

42. Dittner AJ, Wessely SC, Brown RG. The assessment of fatigue: A practical guide for clinicians and researchers. J Psychosom Res. 2004;56:157-170.

43. Radloff LS. The CES-D Scale: a self-report depression scale for research in the general population. Appl Psychol Meas. 1977;1(3): 385-401.

44. Devins GM, Orme CM, Costello CG, et al. Measuring depressive symptoms in illness populations: Psychometric properties of the Center for Epidemiologic Studies Depression (CES-D) scale. Psychology and Health. 1988;2(2):139-156.

45. Zigmond AS, Snaith RP. The hospital anxiety and depression scale. Acta Psychiatr Scand. 1983;67(6):361-370.

46. Bjelland I, Dahl AA, Haug TT, Neckelmann D. The validity of the Hospital Anxiety and Depression Scale. An updated literature review. J Psychosom Res. 2002;52(2):69-77.

47. Sherbourne CD, Stewart AL. The MOS social support survey. Soc Sci Med. 1991;32(6):705-714.

48. Smith G, Della Sala S, Logie RH, Maylor EA. Prospective and retrospective memory in normal ageing and dementia: a questionnaire study. Memory. 2000;8(5):311-321. 
49. Crawford JR, Smith G, Maylor EA, Della Sala S, Logie RH. The Prospective and Retrospective Memory Questionnaire (PRMQ): Normative data and latent structure in a large non-clinical sample. Memory. 2003;11(3):261-275.

50. Kliegel M, Jäger T. Can the prospective and retrospective memory questionnaire (PRMQ) predict actual prospective memory performance? Current Psychology. 2006;25(3):182-191.

51. Broadbent DE, Cooper PF, FitzGerald P, Parkes KR. The Cognitive Failures Questionnaire (CFQ) and its correlates. Br J Clin Psychol. 1982;21(Pt 1):1-16.

52. Wallace JC, Kass SJ, Stanny CJ. The cognitive failures questionnaire revisited: dimensions and correlates. J Gen Psychol. 2002;129(3): $238-256$.

53. Larson GE, Alderton DL, Neideffer M, Underhill E. Further evidence on dimensionality and correlates of the Cognitive Failures Questionnaire. Br J Psychol. 1997;88(1):29-38.

54. Tabachnick BG, Fidell LS. Using Multivariate Statistics. 4th ed. Needham Heights, MA: Allyn \& Bacon; 2001.

55. Farrin L, Hull L, Unwin C, Wykes T, David A. Effects of depressed mood on objective and subjective measures of attention. J Neuropsychiatry Clin Neurosci. 2003;15(1):98-104.

56. Treves TA, Verchovsky R, Klimovitzky S, Korczyn AD. Incidence of dementia in patients with subjective memory complaints. Int Psychogeriatr. 2005;17(2):265-273.
57. Attree EA, Dancey CP, Keeling D, Wilson C. Cognitive function in people with chronic illness: inflammatory bowel disease and irritable bowel syndrome. Appl Neuropsychol. 2003;10(2):96-104.

58. Suhr JA. Neuropsychological impairment in fibromyalgia: relation to depression, fatigue, and pain. J Psychosom Res. 2003;55(4):321-329.

59. Verbaan D, Marinus J, Visser M, et al. Cognitive impairment in Parkinson's disease. J Neurol Neurosurg Psychiatry. 2007;78(11): 1182-1187.

60. Lorusso L, Mikhaylova SV, Capelli E, Ferrari D, Ngonga GK, Ricevuti G. Immunological aspects of chronic fatigue syndrome. Autoimmun Rev. 2009;8(4):287-291.

61. Heesen C, Nawrath L, Reich C, Bauer N, Schulz KH, Gold SM. Fatigue in multiple sclerosis: an example of cytokine mediated sickness behaviour? J Neurol Neurosurg Psychiatry. 2006;77(1):34-39.

62. Fletcher MA, Zeng XR, Barnes Z, Levis S, Klimas NG. Plasma cytokines in women with chronic fatigue syndrome. J Transl Med. 2009;7:96.

63. Raison CL, Lin JM, Reeves WC. Association of peripheral inflammatory markers with chronic fatigue in a population-based sample. Brain Behav Immun. 2009;23(3):327-337.
Psychology Research and Behavior Management

\section{Publish your work in this journal}

Psychology Research and Behavior Management is an international, peerreviewed, open access journal focusing on the science of psychology and its application in behavior management to develop improved outcomes in the clinical, educational, sports and business arenas. Specific topics covered include: Neuroscience, memory \& decision making; Behavior

\section{Dovepress}

modification \& management; Clinical applications; Business \& sports performance management; Social and developmental studies; Animal studies. The manuscript management system is completely online and includes a quick and fair peer-review system. Visit http://www.dovepress. $\mathrm{com} /$ testimonials.php to read real quotes from published authors. 